Cite this: Chem. Commun., 2014, 50,5046

Received 25th October 2013, Accepted 3rd March 2014

DOI: $10.1039 / \mathrm{c} 3 c c 48181 f$

www.rsc.org/chemcomm

\section{High density monolayer of diisocyanide on gold surface as a platform of supported Rh-catalyst for selective 1,4-hydrogenation of $\alpha, \beta$-unsaturated carbonyl compounds $\dagger$}

\author{
S. Jagtap, ${ }^{a}$ Y. Kaji, ${ }^{\text {b }}$ A. Fukuoka ${ }^{a}$ and K. Hara*a
}

\begin{abstract}
A high density monolayer of diisocyanide on gold surface was utilized as a platform of supported Rh catalyst for selective 1,4-hydrogenation of $\alpha, \beta$-unsaturated carbonyl compounds. The catalyst exhibited high turnover numbers in a range of 50000 to 150000 per Rh atom and showed steady catalyst performance over six recycle usages.
\end{abstract}

Self-assembling of organic molecules on surfaces automatically forms ordered and densely packed molecular monolayers. This spontaneous phenomenon can be used as a low-cost method to prepare functional materials for a wide range of applications including catalysts, sensors, photo- and electronic devices. In addition to the ease in preparation as mentioned above, another advantage of using self-assembled monolayers for catalyst preparation is its potential possibility to exhibit novel catalytic performance originated from its high density. For example, adjacent active centers on the top of a monolayer may synergistically enable unique catalytic activity and selectivity. However, such unique catalytic performance of high-density monolayers has been reported in a limited number of publications. ${ }^{1-3}$ Milstein et al. reported that monolayer and LangmuirBlodgett films of a rhodium-bipyridine complex show high catalyst turnover numbers in hydrogenation of acetone as well as a unique selectivity towards acetone in the presence of butanone. ${ }^{1}$ We previously utilized a monolayer of alkanethiolate on gold surface ${ }^{4}$ to prepare a high-density monolayer of rhodiumphosphine complex for dehydrogenative silylation of alcohols and obtained complete selectivity towards primary alcohols over secondary alcohols. ${ }^{3}$ If more examples of advantageous features are demonstrated with high-density monolayer catalysts,

\footnotetext{
${ }^{a}$ Catalysis Research Centre, Hokkaido University, Kita 21 Nishi 10, Kita-ku, Sapporo, Hokkaido 001-0021, Japan.E-mail: hara@cat.hokudai.ac.jp; Fax: +8111706 9139; Tel: +81117069136

${ }^{b}$ Graduate School of Science, Hokkaido University, Kita 10 Nishi 8, Kita-ku, Sapporo, Hokkaido 060-0810, Japan

$\dagger$ Electronic supplementary information (ESI) available: Detailed procedures for catalyst preparation and characterization; space-filling model of catalyst. See DOI: $10.1039 / \mathrm{c} 3 \operatorname{cc} 48181 \mathrm{f}$
}

their potential application in catalysis will be increasingly recognized. We thus envisioned the utilization of a monolayer of isocyanide for catalyst preparation. Compared to commonly used self-assembled monolayers of alkanethiolate on gold surfaces, ${ }^{4}$ monolayers of isocyanide have been much less studied. Although fundamental studies on formation of isocyanide monolayers ${ }^{5}$ as well as microscopic and spectroscopic studies ${ }^{6}$ have been reported, its application has not been extensively explored. Immobilization of ruthenium phthalocyanine on an isocyanide monolayer was reported $;^{7}$ however, application of the metalimmobilized monolayer was not shown. In this study, a denselypacked monolayer of diisocyanide molecule on gold surface was utilized for high-density immobilization of a rhodium complex. The Rh-immobilized monolayer showed high catalyst turnover numbers in selective 1,4-hydrogenation of $\alpha, \beta$-unsaturated carbonyl compounds as well as steady catalyst performance over at least six recycle usages.

As illustrated in Fig. 1, immersion of a gold surface (evaporated on glass) in a $1.0 \mathrm{mM}$ solution of $4,4^{\prime \prime}$-p-terphenyl diisocyanide (TPDI) in $\mathrm{CH}_{2} \mathrm{Cl}_{2}$ for $24 \mathrm{~h}$, followed by washing with $\mathrm{CH}_{2} \mathrm{Cl}_{2}$, afforded [Au]-TPDI (1). ${ }^{5}$ Complexation of $\mathbf{1}$ with $\mathrm{Rh}$ to obtain $[\mathrm{Au}]-\mathrm{TPDI}-\mathrm{Rh}(2)$ was carried out by immersion of

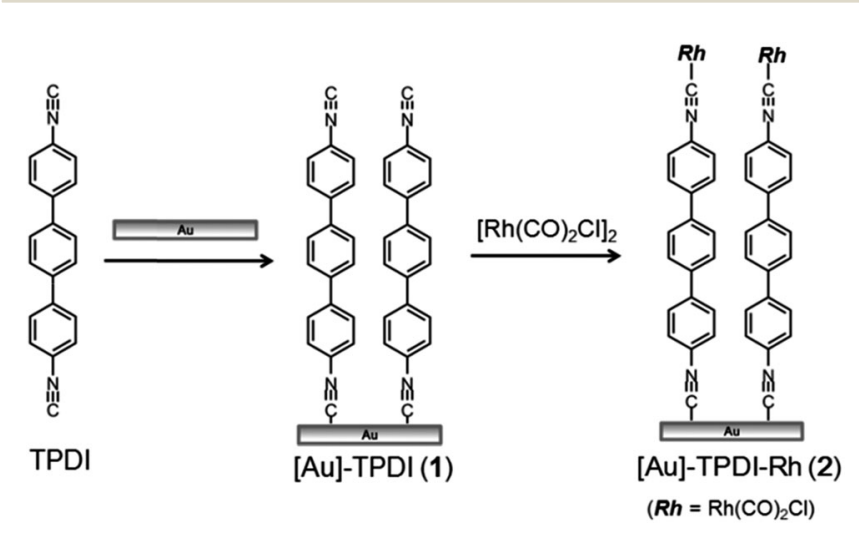

Fig. 1 Preparation of a high-density monolayer of Rh-diisocyanide on gold surface. 


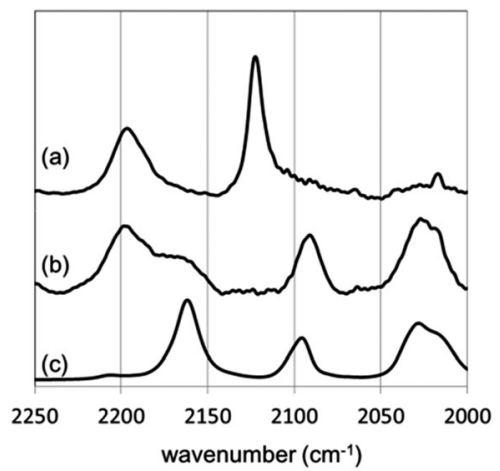

Fig. 2 IR-RAS spectra of (a) [Au]-TPDI (1) and (b) [Au]-TPDI-Rh (2), and (c) FT-IR spectrum of a 2:1 mixture of 4-biphenyl isocyanide (BPI) and $\left[\mathrm{RhCl}(\mathrm{CO})_{2}\right]_{2}$ (isocyanide/ Rh ratio $=1$ ) in $\mathrm{CH}_{2} \mathrm{Cl}_{2}$.

monolayer 1 into a $5.0 \mathrm{mM}$ solution of $\left[\mathrm{Rh}(\mathrm{CO})_{2} \mathrm{Cl}\right]_{2}$ in benzene for $3 \mathrm{~h}$, followed by washing with benzene.

IR-RAS measurement of [Au]-TPDI (1) revealed the stretching modes of both Au surface bound $\left(2195 \mathrm{~cm}^{-1}\right)$ and free $\left(2122 \mathrm{~cm}^{-1}\right)$ isocyanides as shown in Fig. $2 \mathrm{a}^{5}$ In contrast, the IR-RAS spectrum of [Au]-TPDI-Rh (2) (Fig. 2b) showed no peak for the free isocyanide whereas a new peak at $2165 \mathrm{~cm}^{-1}$, which can be assigned to Rh-bound isocyanide, was observed. The peaks appearing at 2025 and $2091 \mathrm{~cm}^{-1}$ are at similar wavenumbers with those of a corresponding mixture of isocyanide and Rh precursor (Fig. 2c), suggesting two carbonyl ligands are bound to the $\mathrm{Rh}$ atom in cis-position in square-planer coordination. These results indicate that all the free isocyanide groups on top of the diisocyanide monolayer (1) were coordinated to $\mathrm{Rh}$ in the preparation of [Au]-TPDI-Rh (2). ICP-MS measurement of [Au]-TPDI-Rh (2) gave a Rh concentration of $0.66 \mathrm{nmol} \mathrm{cm}{ }^{-2}$. Based on this surface concentration of Rh and the assumption of $1: 1$ complex formation between $\mathrm{Rh}$ and isocyanide, a spacefilling model of [Au]-TPDI-Rh (2) can be drawn as shown in Fig. S1 (ESI $\dagger$ ). Considering the sizes of TPDI molecule and the $\mathrm{Rh}$ species, formation of the densely-packed monolayer in [Au]-TPDI (1) and complete Rh complexation in [Au]-TPDI-Rh (2) could be reasonable.

While abundant literature is available on the use of various homogeneous and heterogeneous catalysts for selective hydrogenation of $\alpha, \beta$-unsaturated carbonyl compounds, there are still several problems associated with catalyst recyclability and lower catalyst turnover number. ${ }^{8}$ The catalytic activity of [Au]-TPDI$\mathrm{Rh}$ (2) was thus examined in the hydrogenation of 2-cyclohexen1-one (3) as a model substrate (Table 1). Accordingly, a single chip of [Au]-TPDI-Rh $(2)(5 \mathrm{~mm} \times 5 \mathrm{~mm})$ was placed at the bottom of a high-pressure reactor containing an EtOH solution of $3(12 \mu \mathrm{mol})$. Under these reaction conditions, the substrate/ catalyst ( $\mathrm{Rh}$ atom) ratio is 72000 . The hydrogenation reaction was conducted under $2 \mathrm{MPa}$ at $25{ }^{\circ} \mathrm{C}$ for $12 \mathrm{~h}$ to afford 1,4-hydrogenated product 4 in $77 \%$ yield with only $2 \%$ yield of further hydrogenated product 5, with no formation of 1,2-hydrogenated product (2-cyclohexen-1-ol), so corresponding to a 1,4 -selectivity of $97 \%$ (entry 3 ). Control experiments with gold surface alone (entry 1 ) and [Au]-TPDI (1) (entry 2) gave very
Table 1 Rh-catalyzed selective 1,4-hydrogenation of 2-cyclohexene-1-one ${ }^{a}$

\begin{tabular}{|c|c|c|c|c|}
\hline & 2 & $\begin{array}{l}\text { Rh catalyst } \\
\underset{\mathrm{H}_{2}(2 \mathrm{MPa})}{25^{\circ} \mathrm{C}, 12 \mathrm{~h}}\end{array}$ & + & $\mathrm{OH}$ \\
\hline Entry & Catalyst & Yield $4(\%)$ & Yield 5 (\%) & 1,4-Selectivity (\%) \\
\hline 1 & $\mathrm{Au}$ surface & 5 & 2 & 71 \\
\hline 2 & {$[\mathrm{Au}]-\mathrm{TPDI}(\mathbf{1})$} & 0 & 0 & - \\
\hline 3 & [Au]-TPDI-Rh (2) & 77 & 2 & 97 \\
\hline 4 & {$\left[\mathrm{RhCl}(\mathrm{CO})_{2}\right]_{2}$} & 8 & 15 & 35 \\
\hline $5^{b}$ & {$\left[\mathrm{RhCl}(\mathrm{CO})_{2}\right]_{2}$} & 10 & 19 & 34 \\
\hline $6^{c}$ & $\mathrm{BPI}-\mathrm{RhCl}(\mathrm{CO})_{2}$ & 26 & 4 & 87 \\
\hline
\end{tabular}

${ }^{a}$ Reaction conditions: 2-cyclohexene-1-one $12 \mu \mathrm{mol}$, 2-cyclohexene-1-one/ $\mathrm{Rh}=72000$, EtOH $120 \mu \mathrm{L}, \mathrm{H}_{2} 2 \mathrm{MPa}, 25{ }^{\circ} \mathrm{C}, 12 \mathrm{~h} .{ }^{b}$ Reaction was carried out for $20 \mathrm{~h} .{ }^{c}$ Reaction was carried out for $2 \mathrm{~h} .2: 1$ mixture of 4-biphenyl isocyanide (BPI) and $\left[\mathrm{RhCl}(\mathrm{CO})_{2}\right]_{2}$ was used as catalyst (isocyanide/Rh ratio $=1)$.

sluggish and no reaction, respectively, which implies that catalytically active sites in [Au]-TPDI-Rh (2) are the immobilized $\mathrm{Rh}$ species. The hydrogenation in the presence of $\left[\mathrm{RhCl}(\mathrm{CO})_{2}\right]_{2}$ as a homogeneous catalyst resulted in a very low yield and low 1,4selectivity (entry 4 ). Notably, the reaction with $\left[\mathrm{RhCl}(\mathrm{CO})_{2}\right]_{2}$ after another $8 \mathrm{~h}$ gave no significant increase in yield (entry 5), showing severe deactivation of catalytically active species. Although another homogeneous control experiment using a $2: 1$ mixture of 4-biphenyl isocyanide (BPI) and $\left[\operatorname{RhCl}(\mathrm{CO})_{2}\right]_{2}$ facilitated the hydrogenation reaction, the 1,4 -selectivity was $<90 \%$ even in an initial stage of the reaction where $26 \%$ of 4 was formed (entry 6). These experiments indicate that Rh-diisocyanide monolayer 2 exhibits a uniquely high 1,4-selectivity. The catalyst turnover number obtained with [Au]-TPDI-Rh (2) was 55000 in $12 \mathrm{~h}$. Increase in the reaction scale to $30 \mu \mathrm{mol}$ of 3 afforded a catalyst turnover number of 147000 with 82\% yield of 4 and 98\% 1,4selectivity in $12 \mathrm{~h}$. This experiment demonstrates the feasibility of scale-up of the present catalyst system. For practical purposes, chemical engineering methodologies, such as microfluidic systems, may further enhance the efficiency of the present catalytic system.

Choice of the solvent was found to be particularly important since it determines the activity and the stability of catalyst [Au]TPDI-Rh (2). The reactions in $n$-hexane ${ }^{9}$ and toluene resulted in lower turnover numbers of 25000 and 19000 , respectively. The use of isopropanol gave further sluggish reaction, indicating that a hydrogen transfer step is less likely involved in the reaction mechanism. Although the use of THF afforded a relatively high turnover of 66000 , the catalyst activity of 2 completely disappeared after the second recycle run. In contrast, the catalytic performance of 2 in EtOH was maintained during repeated uses without any significant loss of activity even after the fifth recycle run (Fig. 3). The total catalyst turnover number of 2 in EtOH over the six successive runs reached 892000 .

Application of [Au]-TPDI-Rh (2) for the hydrogenation of various $\alpha, \beta$-unsaturated compounds is summarized in Table 2 . $\alpha, \beta$-Unsaturated ketones and esters were selectively converted into the corresponding $\mathrm{C}=\mathrm{C}$ hydrogenated products in high 


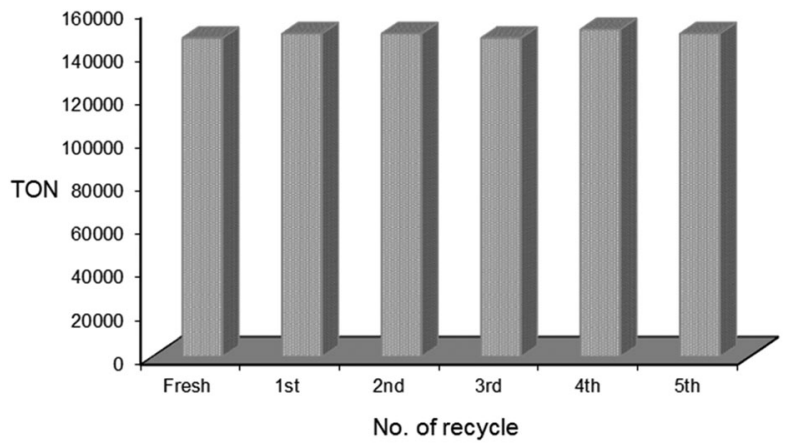

Fig. 3 Catalyst turnover numbers (TON) in recycled uses of [Au]-TPDI-Rh (2) in hydrogenation of 2-cyclohexen-1-one. Reaction conditions: 2-cyclohexene1-one $30 \mu \mathrm{mol}$, 2-cyclohexene-1-one/Rh = 180000 , EtOH $120 \mu \mathrm{L}, \mathrm{H}_{2} 2 \mathrm{MPa}$, $25{ }^{\circ} \mathrm{C}, 12 \mathrm{~h}$.

Table 2 Hydrogenation of various $\alpha, \beta$-unsaturated carbonyl compounds using [Au]-TPDI-Rh (2) ${ }^{a}$

\begin{tabular}{|c|c|c|c|c|}
\hline Entry & Reactant & Product & $\begin{array}{l}\text { Yield } \\
(\%)\end{array}$ & $\begin{array}{l}\text { 1,4-Selectivity } \\
(\%)\end{array}$ \\
\hline
\end{tabular}

1<smiles>O=C1C=CCCC1</smiles><smiles>O=C1CCCCC1</smiles>

77

97<smiles>C=CC(C)=O</smiles><smiles>CCC(C)=O</smiles>

78

3<smiles>C=CC(=O)OC</smiles><smiles>CCC(=O)OC</smiles>

71

4<smiles>C=CC(=O)OCC</smiles><smiles>CCOC(=O)CC</smiles>

5<smiles>O=C(/C=C/c1ccccc1)c1ccccc1</smiles><smiles>O=C(CCc1ccccc1)c1ccccc1</smiles>

98

6<smiles>CCOC(=O)/C=C/c1ccccc1</smiles><smiles>CCOC(=O)CCc1ccccc1</smiles>

99

98

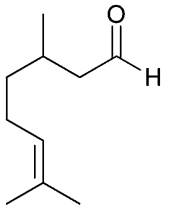

over that of the ketones. More detailed experiments to clarify the origin of the selectivities are now under investigation in our lab.

In summary, a monolayer of diisocyanide on gold surface was utilized to immobilize catalytically active Rh species on the top of the monolayer. IR-RAS and ICP-MS analyses of the Rh-immobilized surface confirmed the formation of a highdensity monolayer of Rh-diisocyanide. The Rh-immobilized monolayer exhibited extremely high catalyst turnover numbers and uniquely high 1,4-selectivity for hydrogenation reaction of various $\alpha, \beta$-unsaturated carbonyl compounds with high recyclability. It can be noted that the catalyst preparation in the present approach using high-density monolayer of metal complexes has unique features against the conventional heterogeneous and homogeneous catalyst systems. Further applications based on the present approach by using simple wet processes are expected to show its versatile significance in various catalytic reactions.

Prof. T. Kawaguchi and Prof. K. Shimazu are gratefully acknowledged for preparation of gold surfaces, Prof. T. Watanabe is acknowledged for ICP-MS measurement and Mr K. Namba for experimental help. This work was financially supported by the Asahi Glass Foundation, JSPS KAKENHI Grant Numbers 23105503, 25105703 and the Global COE Program (Project No. B01: Catalysis as the Basis for Innovation in Materials Science) from MEXT, Japan.

\section{Notes and references}

1 K. Töllner, R. Popovitz-Biro, M. Lahav and D. Milstein, Science, 1997, 278, 2100.

2 I. O. Benítez, B. Bujoli, L. J. Camus, C. M. Lee, F. Odobel and D. R. Talham, J. Am. Chem. Soc., 2002, 124, 4363; A. Pasc-Banu, C. Sugisaki, T. Gharsa, J.-D. Marty, I. Gascon, G. Pozzi, S. Quici, I. Rico-Lattes and C. Mingotaud, Angew. Chem., Int. Ed., 2004, 43, 6174; M. Bartz, J. Küther, R. Seshadri and W. Tremel, Angew. Chem., Int. Ed., 1998, 37, 2466; K. Marubayashi, S. Takizawa, T. Kawakusu, T. Arai and H. Sasai, Org. Lett., 2003, 5, 4409.

3 K. Hara, R. Akiyama, S. Takakusagi, K. Uosaki, T. Yoshino, H. Kagi and M. Sawamura, Angew. Chem., Int. Ed., 2008, 47, 5627.

4 A. Ulman, Chem. Rev., 1996, 96, 1533; A. Ulman, Thin Films: SelfAssembled Monolayers of Thiols, Academic Press, San Diego, CA, 1998; S. Flink, F. C. J. M. van Veggel and D. N. Reinhoudt, Adv. Mater., 2000, 12, 1315; J. J. Gooding, F. Mearns, W. Yang and J. Liu, Electroanalysis, 2003, 15, 81; J. C. Love, L. A. Estroff, J. K. Kriebel, R. G. Nuzzo and G. M. Whitesides, Chem. Rev., 2005, 105, 1103.

5 J. I. Henderson, S. Feng, T. Bein and C. P. Kubiak, Langmuir, 2000, 16, 6183; S. A. Swanson, R. McClain, K. S. Lovejoy, N. B. Alamdari, J. S. Hamilton and J. C. Scott, Langmuir, 2005, 21, 5034.

6 J. A. Boscoboinik, F. C. Calaza, Z. Habeeb, D. W. Bennett, D. J. Stacchiola, M. A. Purino and W. T. Tysoe, Phys. Chem. Chem. Phys., 2010, 12, 11624; J. Boscoboinik, J. Kestell, M. Garvey, M. Weinert and W. T. Tysoe, Top. Catal., 2011, 54, 20; K. Ikeda, N. Fujimoto, H. Uehara and K. Uosaki, Chem. Phys. Lett., 2008, 460, 205; K. Ikeda, J. Sato, N. Fujimoto, N. Hayazawa, S. Kawata and K. Uosaki, J. Phys. Chem. C, 2009, 113, 11816; M. Ito, H. Noguchi, K. Ikeda and K. Uosaki, Phys. Chem. Chem. Phys., 2010, 12, 3156.

yields (entries 1-6). Citral can also be converted to 1,4-hydrogenated product, citronellal, in $65 \%$ yield with $98 \% 1,4$-selectivity (entry 7).

The high selectivities obtained by using [Au]-TPDI-Rh (2) might be associated with preferred adsorption and/or coordination interaction of the starting enones with the catalyst surface
7 V. Huc, J.-P. Bourgoin, C. Bureau, F. Valin, G. Zalczer and S. Palacin, J. Phys. Chem. B, 1999, 103, 10489.

8 F. H. Jardine and G. Wilkinson, J. Chem. Soc. C, 1967, 270; J. Tsuji and K. Ohno, Tetrahedron Lett., 1967, 8, 2173; J. Tsuji and K. Ohno, Synthesis, 1969, 157; V. V. Grushin and H. Alper, Organometallics, 1991, 10, 831.

9 Preliminary XPS results showed the formation of $\mathrm{Rh}(0)$ species by a hydrogenation reaction in hexane, which is most probably the reason for lower catalyst turnover number. 